International Journal of Engineering \& Technology, 7 (4.20) (2018) 557-562
International Journal of Engineering \& Technology
SPC
Website: www.sciencepubco.com/index.php/IJET
Research paper

\title{
The Removal of Terasil Navy Blue Dye from Al-Kut Textile Wastewater Using Membrance Technologies
}

\author{
Hatem Asal Gzar', Zahraa khalid shhaieb ${ }^{1 *}$ \\ ${ }^{1}$ Civil Eng. Department/ College of Engineering/Wasit University \\ *Corresponding author E-mail: zahraakh227@uowasit.edu.iq
}

\begin{abstract}
The current work was devoted to study the operating feasibility using membranes which were manufactured locally, two membrance types were tested nanofiltration (NF) and ultrafiltration (UF) membrane to treat the effluent of Al-kut textile industry. Based on the usage rate in Iraq textile industries, terasil navy blue (TNB) is one of the common disperse dyes discharged in effluent wastewater. Therefore this type of dyes was selected to experience in this study. Parameters such as effects of TNB concentration, feed temperature and operating pressure and its effect on permeate flux noticed and the TNB rejection were investigated. The results show that when using NF system at pressure of $10 \mathrm{bar}$ and when the temperature increased from $25^{\circ} \mathrm{C}$ to $37^{\circ} \mathrm{C}$, it was found that an increase in permeate flux from 46.97 to $50 \mathrm{LMH}$. However, in UF system permeate flux was increased from 41.32 to $45.04 \mathrm{LMH}$. While dye removal was decline in $\mathrm{NF}$ membrane from 96.00 to 95.14 and for UF from 79.50 to 78.67 when the temperature raised from $25^{\circ} \mathrm{C}$ to $37^{\circ} \mathrm{C}$.The pressure state positive effects on dye removal for both membranes, it show that NF membrane is better in treatment than UF membrane.
\end{abstract}

Keywords: Dyeing removal; Terasil Blue dye; NF and UF membrane; wastewater.

\section{Introduction}

Water is considered to be one of the basic elements needed for life to exist. Although it seems abundant on the surface of the earth and due to the increase in population growth and the progress of modern industries, the demand for water has increased continuously. As a result of the increased pollution, Water supplies have become more difficult to get every day[1].

Wastewater contains large amounts of organic and toxic materials generated from dyeing and manufacturing processes. Industrial dyes used in textile factories are considered to be treated difficultly because they contain complex aromatic molecular structures, making these dyes to be more stable and also difficult to be biodegraded $[2,3]$.The water needed by each textile plant was estimated at a huge quantity of about $100-150$ cubic meters per ton. The contaminated water discharged from the factory are very large and need to be treated prior to discharged into the environment, which is to contain dyes, organic materials and mixture of pollutants[4]. Many of the previous studies have shown interest on studying the effectiveness and feasibility of new advanced technologies and study of cost and performance in wastewater treatment. Among these techniques: membrane technology which includes microfiltration (MF), ultrafilration (UF), nanofiltration (NF), reverse osmosis (RO) and other processes such as oxidation processes, electrochemical processes, adsorption and ion exchange. These techniques have proved that it is more efficient and effective in removing the color and COD from wastewater compared to traditional methods [5].

Most of membranes are consider synthetic organic polymers and the difference between one and another is in conditions of preparation until the production of different membranes in terms of size of pores [6]. In this study, a treatment process will be highlighted by locally produced membranes equipped with the University of
Technology in Baghdad governorate. Two models of UF and NF membranes have been used.

Membrane technology is widely used in different industries for separation processes due to their ability to remove color, salt reduction, biological oxygen demand reduction, recovery of latex and PVA. The investment is currently trying to end the traditional treatment to be based on the technology of membranes for being the best commodity and can be used in many treatments in addition to the recovery of valuable products and re-use again and therefore reduce costs [7].In this paper, two types of membrane NF and UF membranes have been used to treated effluent directly from the dye bath from AL-Kut textile factory. The evaluation of UF and NF membranes performance was investigated in two cases, with and without addition of anti-scale acid to the feed samples, and noticed the effect of the anti-scale acid for reducesing the accumulation of fouling on the membrane surface.

\section{Materials and Method:}

\subsection{Experimental apparatus:}

All experiments have been conducted in a pilot plant as shown in Figure (1). Two types of membranes, (UF) and (NF) were used. Each one of these membranes was placed into stainless steel housing. Table (1) shows the characteristics of UF and NF membranes. This system consists of the membrane cell made from stainless steel material, two pumps \{high pressure pump (Parkside Pressure Washer Bulgaria with flow rate $5.5 \mathrm{~L} / \mathrm{min}$ and its maximum speed was $2850 \mathrm{rpm}$ ) before the membrane cell, a pump with a low pressure (Ritek diaphragmpump USA with work flow $28 \mathrm{LPH}$ ) was used to dose the acid to clean membrane\}, two Pressure gages and finally valves with two flow meters, were also used. 
Table 1: The characteristics of UF and NF membranes used in the present study.

\begin{tabular}{|c|c|c|}
\hline Membrane & Nanofiltration & Ultrafiltration \\
\hline Membrane type & PPSU 20\% - PVC 6\% & PPSU 15\% \\
\hline Supplier & University of Technology, Baghdad, Iraq \\
\hline $\begin{array}{c}\text { Effective filtration } \\
\text { area }\left(\mathrm{m}^{2}\right)\end{array}$ & $1.452^{*} 10^{-3}$ & $1.452 * 10^{-3}$ \\
\hline Porosity \% & 49.77 & 42.52 \\
\hline Thickness $(\mu \mathrm{m})$ & 86.85 & 93.95 \\
\hline
\end{tabular}

\section{Experimental:}

Experiments were carried out in several different steps: in the first step, samples were taken from Al-Kut Textile Factory. After the dyeing process is completed, the rinsing process start in three consecutive stages. The difference between each rinse and the other is half an hour. Therefore, the concentration of the pigment in these stages varies and starts gradually decreasing. Therefore, samples were taken from each stage to study the effect of (TNB) dye concentration on the rejection coefficient. These experiments were conducted under different operating pressures. Three experimental pressures were applied in case of using UF membrane (2, 4 and 6 bar). However, six experimental pressures in case of NF membrane $(4,6,8,10,12$ and 14 bar) are used. The experiments were utilized to study the effect of pressure on the rejection factor of the membrane and the best pressure for high efficiency and suitable flux. Two different temperatures $\left(25^{\circ} \mathrm{C}\right.$ and $\left.37^{\circ} \mathrm{C}\right)$ were tested to investigate the seasonal effect of winter and summer seasons on the treatment process as well as on membrane performance. Samples were collected for analysis every 180 minutes for each used pressure and at every 30 minutes for the permeate flux were recorded.

Table2: The characteristics of the effluent of AL-Kut textile factory used in the present study.

\begin{tabular}{|c|c|c|}
\hline Parameter & $\begin{array}{c}\text { Actual level of dye bath } \\
\text { effluent used in NF study }\end{array}$ & $\begin{array}{c}\text { Actual level of dye bath } \\
\text { effluent used in UF study }\end{array}$ \\
\hline Colour $(\mathrm{pt}-\mathrm{co})$ & 350 & 361 \\
\hline TDS mg/l & 656 & 630 \\
\hline TSS mg/l & 53 & 58 \\
\hline PH & 6.8 & 6.91 \\
\hline Turbidity NTU & 58 & 64 \\
\hline EC $\mu \mathrm{s} / \mathrm{cm}$ & 1335 & 1311 \\
\hline ABS & 0.52 & 0.53 \\
\hline COD & 308 & 302 \\
\hline
\end{tabular}

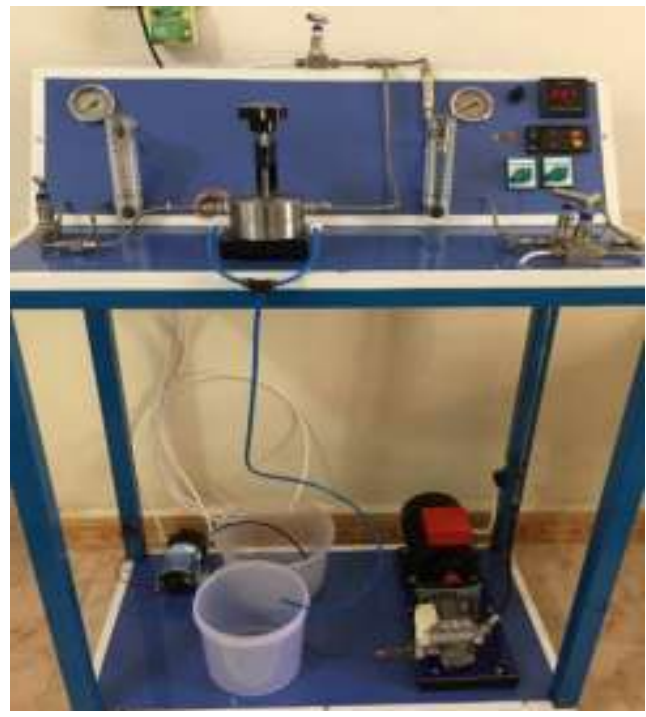

Fig 1: photographic view of the pilot plant.

\section{Analytical methods:}

At each experiment and for varied pressures that is work on it, the flux was collected in a beaker after every 30 minutes and then measured in a volumetric flask and it was analysed by analytic equipment. The color that consider as a function for the dye concentration has been determined spectrophotometrically at a wavelength $663 \mathrm{~nm}$ using UV-1100 spectrophotometer (Germany model 2008) which measures the light absorbency of a dye feed. One of the important parameters that give a necessary indicator for water reuse is chemical oxygen demand (COD) and it was determined through spectrophotometric tests after the samples oxidation with acid solution at $150^{\circ} \mathrm{C}$ and time two hour Figure (2) illustrates the standard curve of light absorbency vs. various concentrations of TNB dye that prepared laboratory. The factor of rejection $(\mathrm{R})$ of each species was calculated as [8]:

$\% \mathrm{R}=\left(1-\frac{C_{P}}{C_{R}}\right) * 100$

Where: $\mathrm{R}$ is rejection factor (\%), $C_{P}$ : permeate concentration (mg/L), $C_{R}$ : feed concentration (mg/L). The permeate flux (J) of the membrane is calculated as:

$\mathrm{J}=$

$\frac{Q_{P}}{A}$

Where: $\mathrm{J}$ is the permeate flux $\left(\mathrm{L} / \mathrm{m}^{2} . \mathrm{h}\right), Q_{P}$ is the permeate flow rate per hour and $A$ is active surface area of membrane $\left(\mathrm{m}^{2}\right)$.

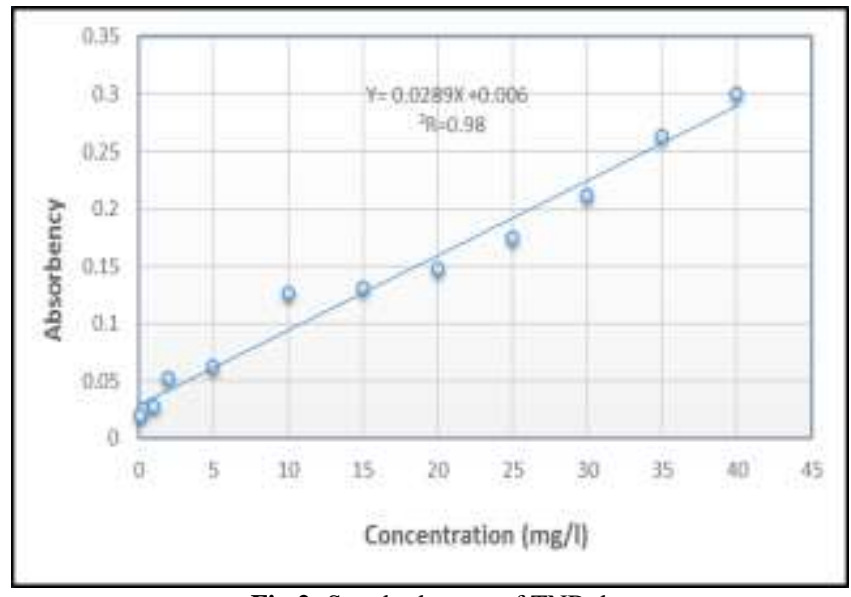

Fig 2: Standard curve of TNB dye

\section{Results and discussion:}

\subsection{Effect of Dye Concentration on the Percentage Re- moval of dye:}

Figures (3) and (4) illustrates the percentage of TNB dye removal at different concentrations $(11.99,17.59$ and $28.34 \mathrm{mg} / \mathrm{l})$ using the NF membrane at a constant pressure of 10 bar. The dye removal was recorded as $96.40 \%, 97.10 \%$ and $98.03 \%$ respectively.

The percentage of dye removal increased when the concentration of dye increased. Concentration of the feed change the viscosity, density and diffusivity of the waste solution will change and that may be effect on the removal efficiency. This increase in concentration of the feed sample will lead to a corresponding increase in concentration polarization which is a result of the buildup of layer of dye on the membrane surface, so higher is the feed concentration lead to higher percentage of dye removal. However, for using UF membrane in Figure 4 to the flowing concentration (11.59 $\mathrm{mg} / \mathrm{l}, 18.36 \mathrm{mg} / \mathrm{l}$ and $27.88 \mathrm{mg} / \mathrm{l}$ ) at constant pressure of 4 bar and the percentage of dyes removal were obtained are $78.47 \%, 80.71$ and 82.00 respectively, these results are agree with the findings of $[9,10,11]$. 


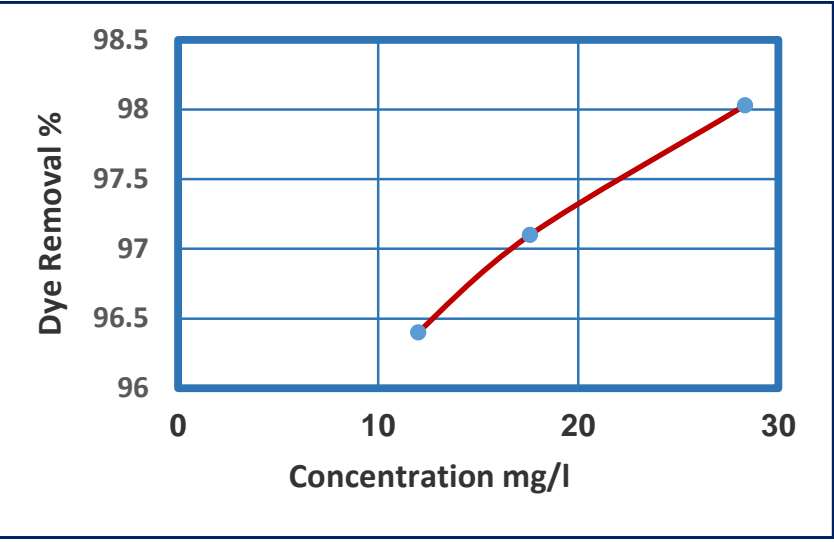

Fig 3: Dye removal percentage at different concentrations using NF membrane at (pressure $=10$ bar)

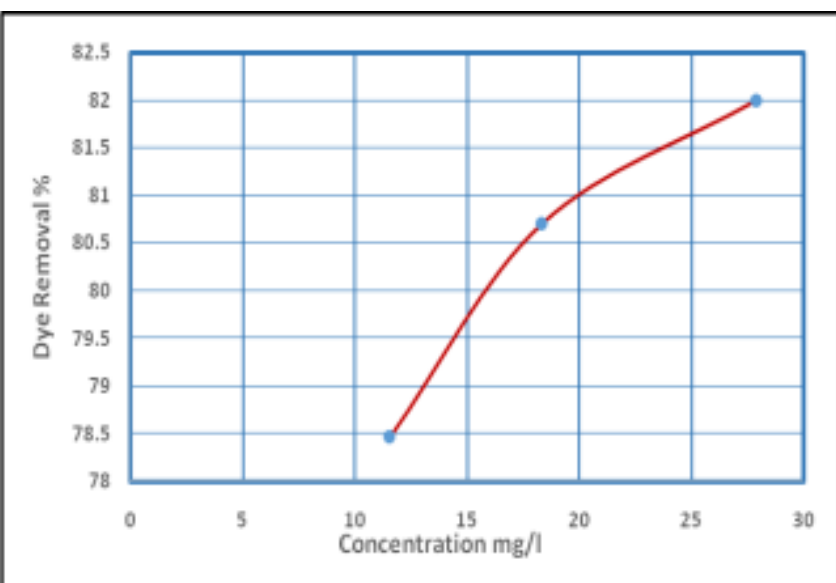

Fig 4: Dyes Removal percentage at different concentrations using UF membrane at (pressure $=4$ bar)

\subsection{Effect of pressure on dye removal:}

Pressure operating has a high effect on the percentage removal of dyes as shown in Figures (5) and (6). In case of using NF membrane, when the pressure was increased from 4 bar to 14 bar, a rise in the removal level, especially at concentration of $17.09 \mathrm{mg} / \mathrm{l}$ the percentage removal of dyes were ranged from $93.24 \%$ to $97.70 \%$, while an increase in pressure from 2 bar to 6 bar for using UF membrane and dyes removal were changed from $78.94 \%$ to $82.00 \%$.

It was found that there is a positive relationship between the percentage of removal and the increasing pressure, this indicates that the dynamic force improves with increased pressure and could lead to enhance the driving force that will reduce the resistance during the membrane and leads to membrane compaction as well as control the thickness of the layer.

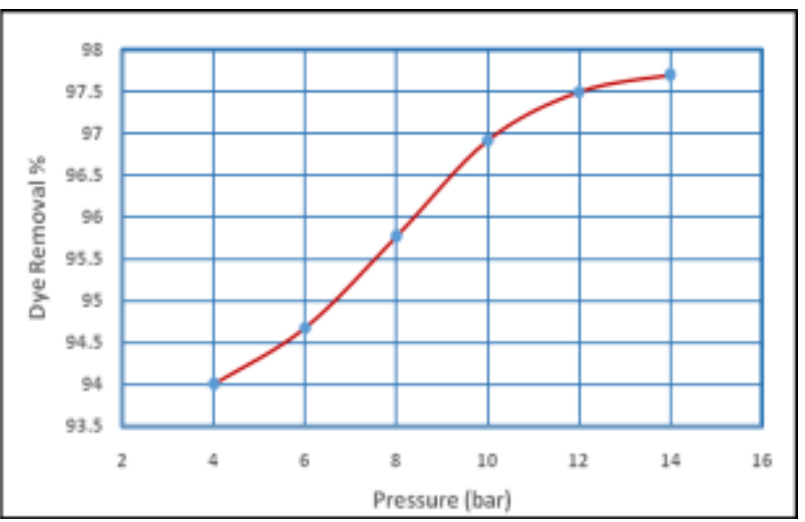

Fig 5: The Effect of operating pressure on percentage of Dye removal (NF, TNB)

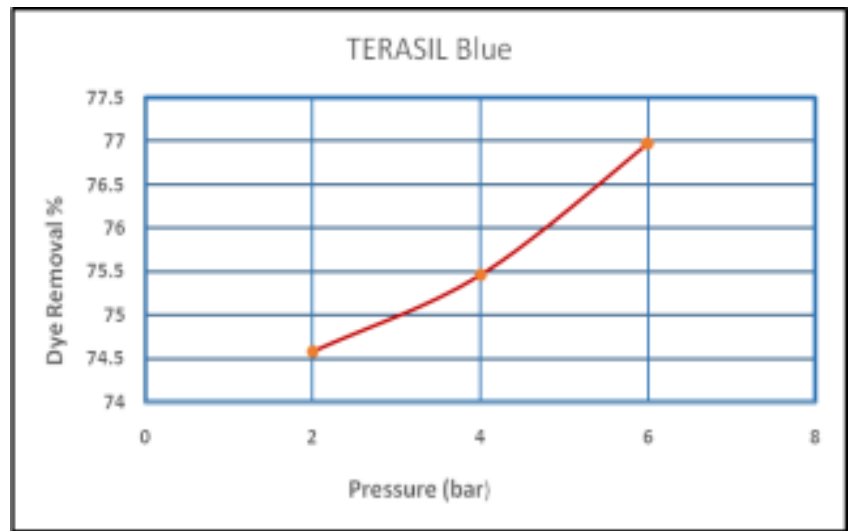

Fig 6: The Effect of operating pressure on percentage of Dye removal (UF, TNB)

\subsection{Effect of Feed Temperature on dye removal:}

Temperature of the feed is an important factor influencing the process of membrane performance Figures (7) and (8) illustrates the difference in the efficiency of dye removal when the temperature rise from $25^{\circ} \mathrm{C}$ to $37^{\circ} \mathrm{C}$ it was observed that there is an inverse relationship between temperature and removal process. In case of NF membrane removal ratio decreased from $96.92 \%$ to $96.15 \%$ at pressure 10 bar while in UF membrane it was decline from $80.71 \%$ to $79.05 \%$ at pressure 4 bar [12].

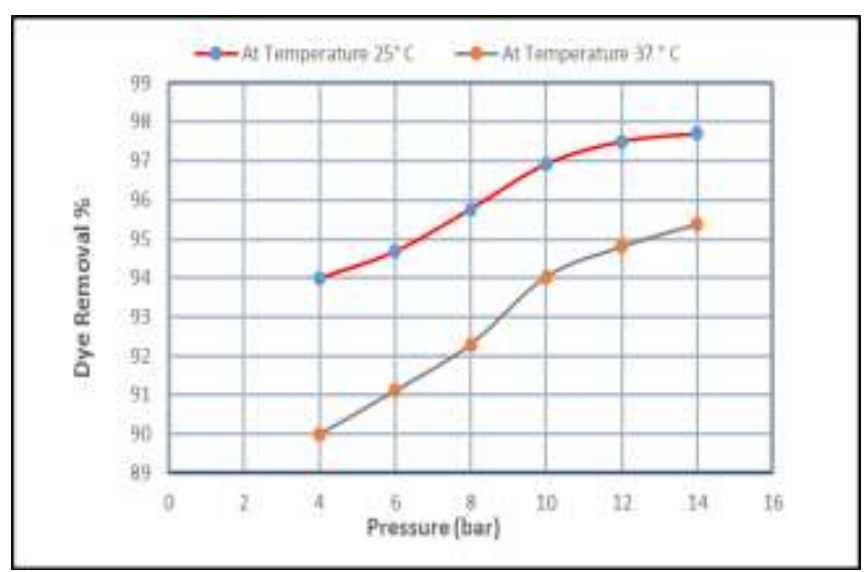

Fig 7: Effect of feed temperature on percentage removal of dye with NF membrane

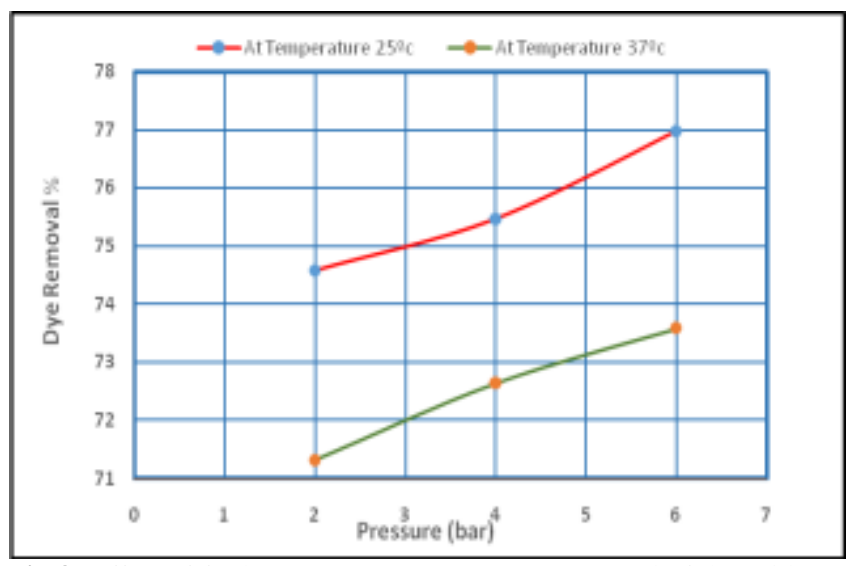

Fig 8: Effect of feed temperature on percentage removal of dye with UF membrane 


\subsection{Effect of Pressure and feed Temperature on Perme- ate Flux:}

Figures (9) and (10) shows the effect of pressure and feed temperature on the permeate flux where it has a positive effect both of them, from these figures it can be seen that the pressure is proportional to the permeate flux and according to the increase in driving force and overcoming membrane resistance this will lead to expected increasing in permeate flux $[\mathbf{1 3}, \mathbf{1 4}]$. In this study, maximum flux were obtained at 14 bar and it reached in NF membrane to $51 \mathrm{LMH}$ and for using UF membrane at 6 bar was $42.56 \mathrm{LMH}$. While the flux permeation increases with increasing in feed temperature and it may be attributed to the following effects: by in creasing the temperature of the feed that would be lead to reduce the viscosity of the permeate and this will causing high diffusion rate of permeate through membrane. Also the increase in feed temperature consider an influence factor that increased the pore radius of membrane. The increase in pore sizes lead to reductions in contaminant (organic matter, salts, natural, hardness, etc) removal beside to water permeability of the membrane defiantly will be increases with increasing temperature [15].

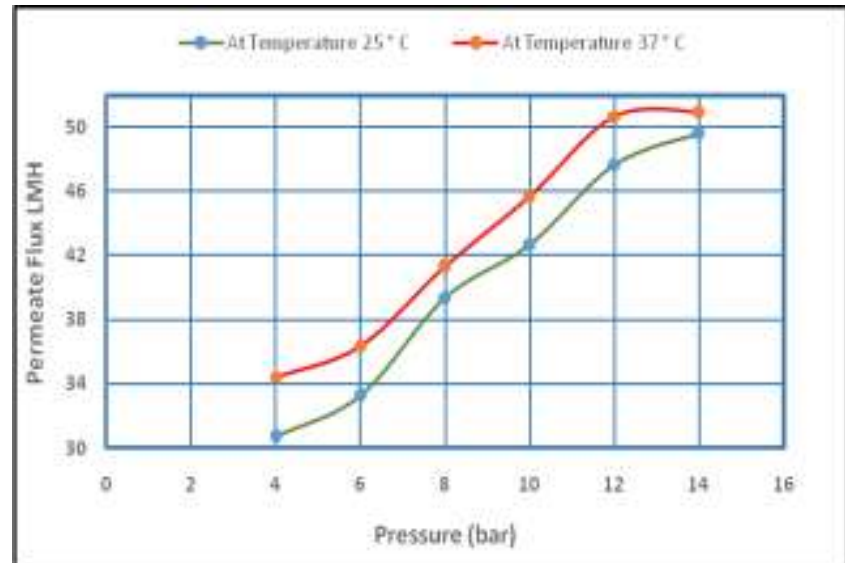

Fig 9: Effect of Feed Temperature at Different Operating Pressure on permeate flux (NF membrane)

$$
\longrightarrow \text { At temperature } 25^{\circ} \mathrm{C} \longrightarrow \text { At temperature } 37^{\circ} \mathrm{C}
$$

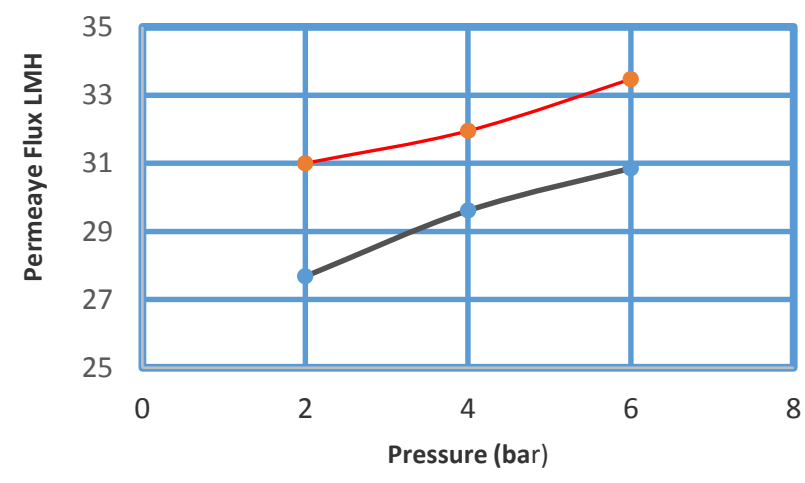

Fig 10: Effect of Feed Temperature at Different Operating Pressure on permeate flux (UF membrane)

\subsection{COD removal:}

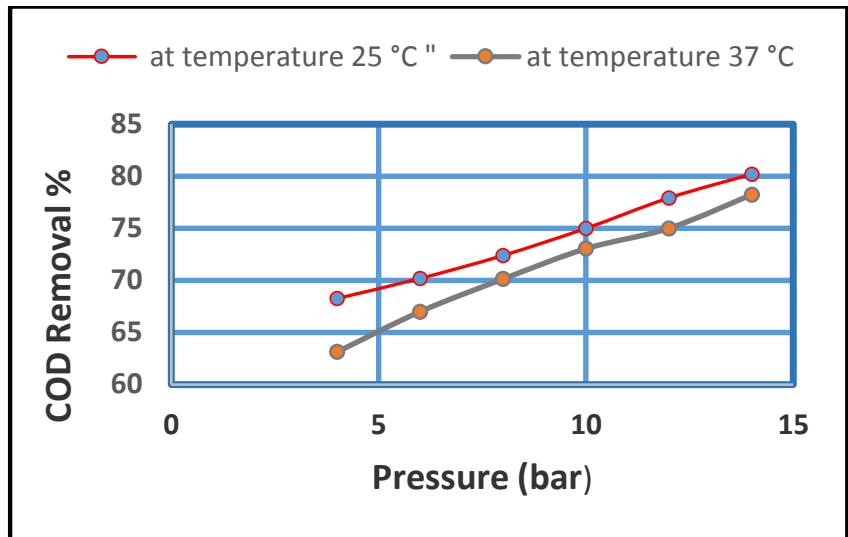

Fig11: Effect of Applied Pressure and feed temperature on COD Removal using NF membrane

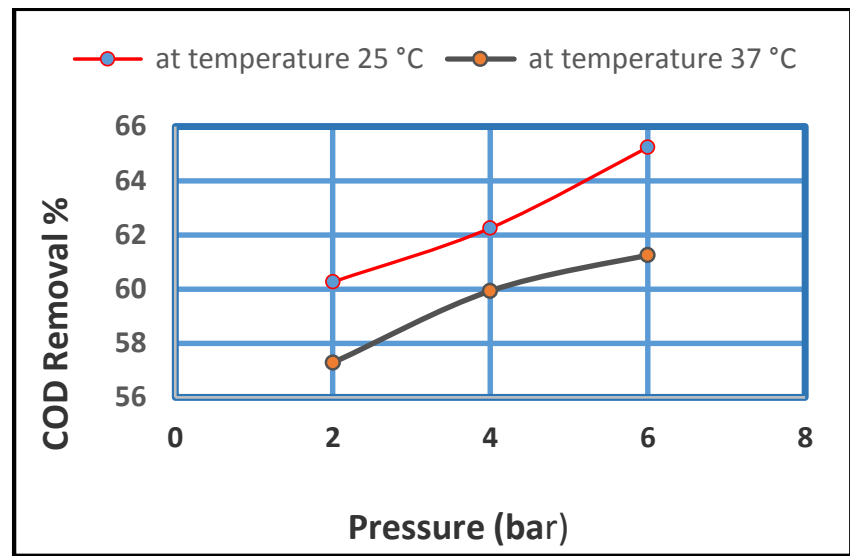

Fig 12: Effect of Applied Pressure and feed temperature on COD Removal using UF membrane

\subsection{Removal of Turbidity and Total Suspended Solid (TSS):}

Table (3) shows the removal ratio of TSS and Turbidity for the TNB feed sample where it is obviously seems that the Nanofiltration performance in removal is better than Ultrafiltration. NF membrane was more efficient and agrees with the specific criteria for reuse of water than UF membrane and this related to the pore size which leads to the transit of organic substances and pollutants more through the membrane surface.

Table (3): Turbidity and TSS retention by NF and UF membranes

\begin{tabular}{|c|c|c|c|}
\hline \multicolumn{4}{|c|}{ NF membrane (at pressure 10 bar) } \\
\hline Parameter & Feed & Permeate & R \% \\
\hline TSS mg/l & 78 & 15.5 & $80.13 \%$ \\
\hline Turbidity NTU & 58 & 8.2 & $85.86 \%$ \\
\hline \multicolumn{4}{|c|}{ UF membrane (at pressure 4 bar) } \\
\hline Parameter & Feed & Permeate & R \% \\
\hline TSS mg/l & 58 & 14.84 & $74.41 \%$ \\
\hline Turbidity NTU & 64 & 9.83 & $84.64 \%$ \\
\hline
\end{tabular}

\section{Evaluation of NF and UF membranes per- formance after addition of anti-scale acid to the Feed samples:}

Discharge is an important issue and must be taken into account, in addition to solving the problem of pollution caused by waste water, permeate flux is also important because of water scarcity, therefore pay attention to the problem of fouling that blocks the pores of the membrane surface and reduces the life of membrane in addition to reducing the resulting flux. In order to control this 
fouling, in this study anti-scale acid was used to made the feed solution in continuous movement thereby minimize the accumulation of organic materials on the membrane, which hinders the filtering process and reduce the flux. As we see in Figures (13) and (14) have been noticed improvement in behavior of permeate flux than was observed before the use of acid especially in high operating pressures. This result is agree with the finding [17].

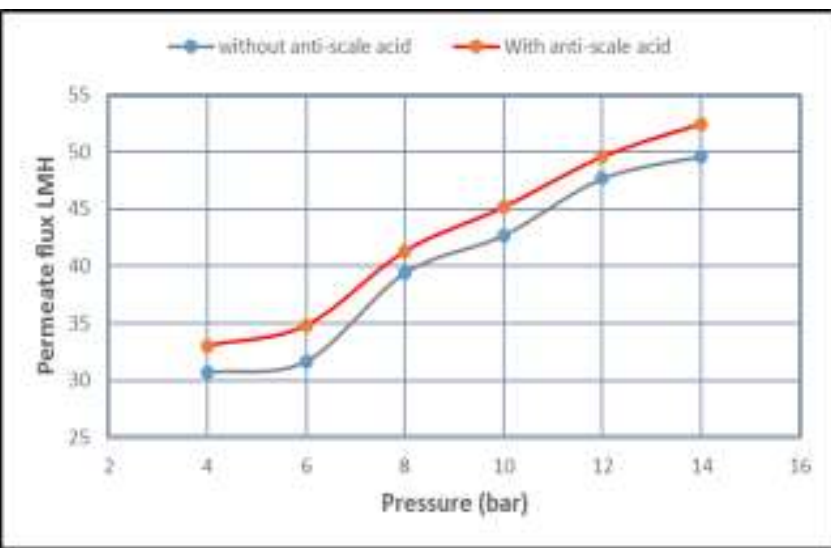

Fig 11: Effect of anti-scale on permeate flux at Different operating (NF membrane)

$\longrightarrow$ Without anti-scale acid $\_$- With anti-scale acid

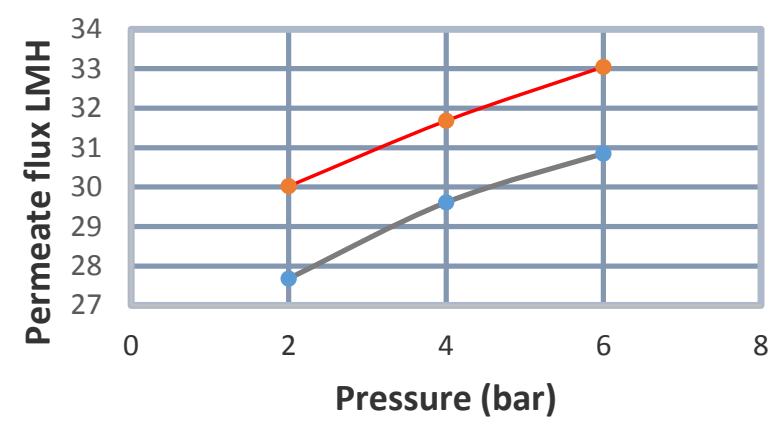

Fig 12: Effect of anti-scale acid on permeate flux at Different operating (UF membrane)

\section{Prediction of modified fouling index (MFI) for NF and UF membranes processes:}

The slope of an inverse flow rate (1/Q) versus cumulative volume (V) represent the MFI as shown in equation below:

$\frac{1}{Q}=a+M F I * V$

MFI was investigated in this study systematically, one of the reasons for this hindrance is the cake formation due to suspended and colloidal matter (particulate fouling)[18-19]

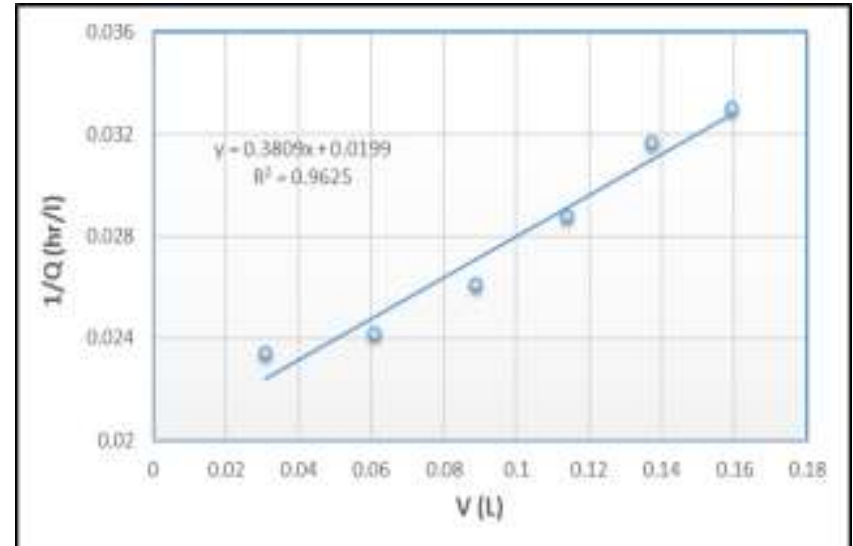

Fig 13: Evaluation of MFI for waste water using TNB dye (NF membrane, at 10 bar)

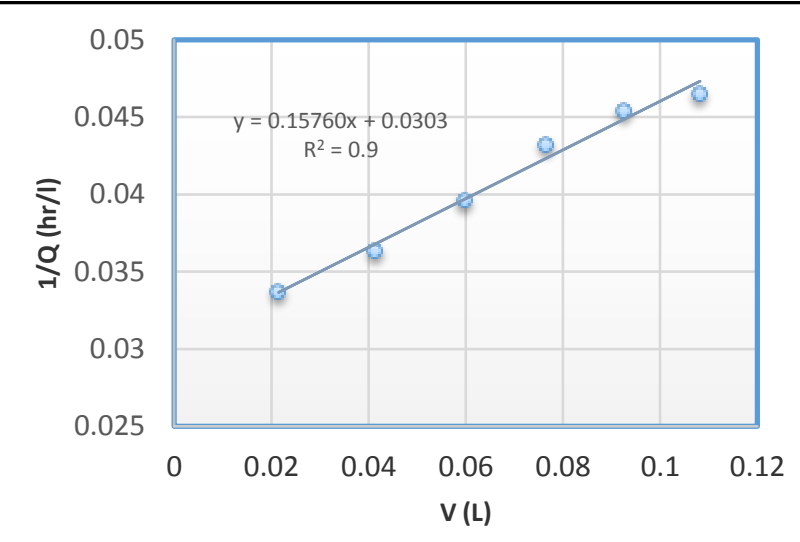

Fig 14: Evaluation of MFI for waste water using TNB dye (UF membrane, at 4 bar)

\section{Conclusion:}

From series of the experiential teststhe following conclusion can be drawn: NF and UF membranes can be an effective tools to be used in treated the effluent waste water of Al-kut textile industry, where the use of NF and UF membrane has been proven to be effectivein removal of dye from wastewater beside to reduction in chemical oxygen demand (COD) to be at the required limits. Dye removal was positively related to applied pressure while inversely related to feed temperature. From the results it show that the dye concentration state inversely effect on permeate flux while applied pressure as well as feed temperature have positive impact on permeate flux for both membranes NF and UF, beside to addition of anti-scale acid to the solution which contributed to increase flux by reduce the accumulation of fouling. When compared between these two types it demonstrate that the behaver of NF system has higher rejection than UF system but the last has higher permeate flux due to the nature of the UF membrane and surface pores compared with NF membrane.

\section{References}

[1] Allegre, C., Mouline, P., Maisseu, M., \& Charbit, F., 2006). Treatment and reuse of reactive dyeing effluents. J. Memb. Science. 269: $15-17$.

[2] Patnaik P., (1996). A Comprehensive Guide to the Hazardous Properties of Chemical Substances. 1st edition. New York: John Wiley \& Sons, Inc.

[3] Kim TH, Lee Y, Yang J, Park C., (2004) Decolorization of dye solutions by a membrane bioreactor (MBR) using whit-rot Fungi. Desalination, 168: 287-293.

[4] G. Eremektar, H. Selcuk \& S. Meric, (2007). Investigation of the Relation between COD Fractions and the Toxicity in a Textile Fin- 
ishing Industry Wastewater: Effect of Preozonation, Journal of Desalination, $211: 314-320$

[5] Kestioglu, K. \& Yalili, M., (2006). Treatability of Textile Industry Wastewater with High COD Content by Chemical Precipitation and Adsorption, Ekoloji Journal, 15(59): 27-31.

[6] Pinnau, I., Freeman, B. D., (2000). In Formation and Modification of Polymeric Membranes, Symposium Series 744; American Chemical Society: Washington D.C., pp 1 -22.

[7] Hassani, A. H., Mirzayee, R., Nasseri, S., Borghei, M., Gholami, M., \& Torabifar, B., (2008). Nanofiltration process on dye removal from simulated textile wastewater. International journal of environmental science \& technology, 5(3): 401-408.

[8] Woerner, D. L. (2003). "Membrane technology in textile operation Koch membrane systems". Wilmington, MA.

[9] Al-Aseeri, M., Bu-Ali, Q., Haji, S., \& Al-Bastaki, N. (2007). Removal of Acid Red and sodium chloride mixtures from aqueous solutions using nanofiltration. Desalination, 206(1-3), 407-413.

[10] Akbari, A., Remigy, J. C., \& Aptel, P. (2002). Treatment of textile dye effluent using a polyamide-based nanofiltration membrane. Chemical Engineering and Processing: Process Intensification, 41(7), 601-609.

[11] Koyuncu, I. (2002). Reactive dye removal in dye/salt mixtures by nanofiltration membranes containing vinylsulphone dyes: effects of feed concentration and cross flow velocity. Desalination, 143(3), 243-253.

[12] Cadotte, J. E., Petersen, R. J., Larson, R. E., \& Erickson, E. E. (1980). A new thin-film composite seawater reverse osmosis membrane. Desalination, 32, 25-31.

[13] Gholami, M., Nasseri, S., Alizadehfard, M., \& Mesdaghinia, A. (2003). Textile dye Removal by Membrane Technology and Biological Oxidation. Water quality research journal of Canada, 38(2): 379-391

[14] Tang, C., \& Chen, V. (2002). Nanofiltration of textile wastewater for water reuse. Desalination, 143(1), 11-20.

[15] Nilsson, M. Lipnizki, F., Trägårdh, G., \& Östergren, K., (2008). Performance, Energy and Cost Evaluation of a Nanofiltration Plant Operated at Elevated Temperatures. Separation and Purification Technology, 60(1): 36-45

[16] Lopes, C. N., Petrus, J. C. C., \& Riella, H. G., (2005). Color and COD retention by nanofiltration membranes. Desalination, 172(1) 77-83.

[17] Peng, Y., Ge, J., Li, Z., \& Wang, S. (2015). Effects of anti-scaling and cleaning chemicals on membrane scale in direct contact membrane distillation process for RO brine concentrate. Separation and Purification Technology, 154: 22-26.

[18] Lee, S., Cho, J., \& Elimelech, M. (2005). Combined influence of natural organic matter (NOM) and colloidal particles on nanofiltration membrane fouling. Journal of Membrane Science, 262(1-2), $27-41$.

[19] Alhadidi, A., Kemperman, A. J. B., Blankert, B., Schippers, J. C., Wessling, M., \& Van der Meer, W. G. J. (2011). Silt density index and modified fouling index relation, and effect of pressure, temperature and membrane resistance. Desalination, 273(1): 48-56. 